\title{
Mechanical Properties and Micro Structure of Cement Concrete in Freeze-Thaw Environment
}

\author{
Xin jian $\mathrm{Lv}^{1}$, Lei $\mathrm{Yu}^{2,3}$ and Ming ming $\mathrm{Chai}^{2,3^{*}}$ \\ ${ }^{1}$ Shandong Hi-speed Construction Management Group Co., Ltd, Jinan, Shandong, 250014, China \\ ${ }^{2}$ Research Institute of Highway Ministory of Transport, Beijing, Beijing, 100088, China \\ ${ }^{3}$ Beijing Xinqiao Technology Development Co., Ltd, Beijing, Beijing, 100088, China
}

\begin{abstract}
In order to find the declay law of mechanical property and the performance difference after salty water and fresh water freeze-thaw cycle, freeze-thaw cycle environments under the salty water and fresh water are simulated. The compressive strength, dynamic elastic modulus and the mass lost are tested. The pore structure parameters are also tested by MIP. Plot the pore diameter distribution curve. The result shows that the compressive strength and dynamic elastic modulus are all decreased. The degree of these two properties decreasing under salty water freeze and thaw recycle is more than the one under fresh water. The parameters of porosity and critical pore diameter become larger. The amount of pores whose diameter is between $100 \mathrm{~nm}$ and $1000 \mathrm{~nm}$ increase. The amount of pores whose diameter is under $100 \mathrm{~nm}$ decrease. The deteriorate degree of pore structure is deeper in salty water than in fresh water.
\end{abstract}

\section{Background}

According to the natural zoning of highways, nearly twothirds of the country will be affected by the freeze-thaw cycle. Especially in the north, The freezing and thawing of deicing salt in winter will affect the concrete structure, the marine concrete is also affected by the salt freezing environment[2].In the fresh water level changing zone, The ponds, cooling towers of power stations, abutments and other structures in rivers will be affected by the freezethaw cycles in the fresh water level changing zone[3].

The bridge concrete guardrail is easily damaged by salt freezing, the lower components such as bridge piers are easily affected by the freeze-thaw cycle of fresh water. So we should treat different components differently when do the durability design of cement concrete. Especially for the large span bridges of expressway, the requirements for the flexural performance of concrete are high. When the expressway is located in the western mountainous area, the anti-cracking performance requirements of the bridge deck pavement concrete is also relatively high because of the dry and windy weather.

Based on the analysis of pore structure, Zhang Yongcun and Li Qingning studied the frost resistance performance of concrete according to the national standard quick freezing method, that is, the fresh water freezing-thawing method[4]. Bowers proposed the "hydrostatic pressure hypothesis" and the "osmotic pressure hypothesis" about the mechanism of concrete destruction under freeze-thaw cycle [5].

According to the current research results, the fresh water immersion method mentioned in the national standard is adopted in most of the freeze-thaw cycle tests, which is not conducive to the durability design of cement concrete components. At present, the mechanism of freeze-thaw damage of concrete is still confined to the theory of crystal pressure and osmotic pressure, and the research on the decay of concrete mechanical properties from the perspective of microscopic pore structure is relatively rare. In the research of freeze-thaw cycle simulation of specimens soaked in brine, there are few studies on the decay nature of mechanical properties from the decay mechanism of microscopic pore structures. Aims at the common salty water freeze-thaw cycle and fresh water freeze-thaw cycle in the natural environment, the two different freeze-thaw cycle environments are simulated by laboratory experiments in this paper. By testing the compressive strength of concrete, dynamic elastic modulus, micro pore structure parameters, pore diameter distribution, the influence law of micro pore structure decay on the concrete mechanical properties will be explored, and the different influence under salty water freeze-thaw cycle and fresh water freeze-thaw cycle environment will be distinguished. This study will provide the theoretical support for durability design of concrete in different freeze-thaw environments.

\section{Test}

\subsection{Raw materials and mix ratio}

\subsubsection{Raw materials.}

The 42.5 ordinary portland cement produced by Huaxin cement factory is used in the study, and the physical and 
chemical properties of the cement are shown in Table 1. The fineness in the table is the sieve residue of $80 \mu \mathrm{m}$ square hole sieve tested by the negative pressure sieve method.

The fly ash used is type $\mathrm{F}$ class I produced by Shandong Huaneng company, and the technical indexes are shown in Table 2. The fineness in the table is the sieve residue of $45 \mu \mathrm{m}$ square hole sieve tested by the negative pressure sieve method. In this research, fine aggregate used is ordinary river sand with fineness modulus: 2.8, while the coarse aggregate using crushed stone produced in Hebei Sanhe with particle size distribution: 5mm$20 \mathrm{~mm}$. By the experiments, the water absorption of the coarse aggregate is $0.4 \%$, and the mud content is $0.3 \%$, the elongated particles content is $5.4 \%$, the crushing value is $20.4 \%$. The water in the test used is drinkable tap water. We also used the water reducing agent and air entraining agent as the admixture. The water reducing agent is polycarboxylic acid type with a high performance waterreducer which the solid content is $35 \%$ and the water reduction rate is $20 \%$. The air entraining agent is rosin, When the proportion of the rosin air entraining agent is $0.1 \%$, the air content of fresh concrete is about $4 \%$.

Table 1. Physical and chemical properties of cement.

\begin{tabular}{|c|c|c|c|c|c|c|c|c|}
\hline \multicolumn{2}{|c|}{$\begin{array}{l}\text { Setting time } \\
\text { (h:min) }\end{array}$} & \multirow{2}{*}{$\begin{array}{c}\text { Fineness } \\
(\%)\end{array}$} & \multirow{2}{*}{ Stability } & \multicolumn{2}{|c|}{$\begin{array}{c}\text { Compressive } \\
\text { strength (MPa) }\end{array}$} & \multicolumn{2}{|c|}{$\begin{array}{l}\text { Flexural strength } \\
(\mathrm{MPa})\end{array}$} & \multirow{2}{*}{$\begin{array}{c}\text { Water } \\
\text { consumption for } \\
\text { standard } \\
\text { consistency }(\%)\end{array}$} \\
\hline $\begin{array}{l}\text { Initial } \\
\text { setting }\end{array}$ & $\begin{array}{c}\text { Final } \\
\text { setting }\end{array}$ & & & $3 d$ & $28 \mathrm{~d}$ & $3 d$ & $28 \mathrm{~d}$ & \\
\hline $2: 55$ & $4: 10$ & 3.1 & Qualified & 27.5 & 48.6 & 5.9 & 9.2 & 27.5 \\
\hline
\end{tabular}

Table 2. Technical index of fly ash.

\begin{tabular}{ccccc}
\hline $\begin{array}{c}\text { Water demand } \\
\text { ratio (\%) }\end{array}$ & Water content (\%) & $\begin{array}{c}\text { Loss on ignition } \\
(\%)\end{array}$ & Stability & Fineness (\%) \\
\hline 90 & 0.4 & 1.8 & Qualified & 4.5 \\
\hline
\end{tabular}

\subsubsection{Test Mix Proportion.}

In this study, the content of the fly ash is $15 \%$, and the air entraining agent are used to make the air content of concrete about $4 \%$. The design strength grade of concrete is $\mathrm{C} 50$, and the mix proportion for test is shown in Table3.During the test, the slump of fresh concrete should be controlled $100 \mathrm{~mm} \pm 30 \mathrm{~mm}$.

Table 3. Mix proportion of concrete / $\left(\mathrm{kg} / \mathrm{m}^{3}\right)$.

\begin{tabular}{ccccccc}
\hline Cement & Fly ash & Water & Sand & $\begin{array}{c}\text { Crushed } \\
\text { stone }\end{array}$ & $\begin{array}{c}\text { Water } \\
\text { reducing } \\
\text { agent }\end{array}$ & $\begin{array}{c}\text { Air } \\
\text { entraining } \\
\text { agent }\end{array}$ \\
\hline 540 & 80 & 220 & 570 & 1065 & 5.4 & 0.054 \\
\hline
\end{tabular}

\subsection{Specimen making and numbering}

There are two types of concrete specimen size required for the test. The specimen size of $100 \mathrm{~mm} \times 100 \mathrm{~mm} \times 400$ $\mathrm{mm}$ is used to measure the dynamic elastic modulus, and the specimen size of $100 \mathrm{~mm} \times 100 \mathrm{~mm} \times 100 \mathrm{~mm}$ is used to test the compressive strength. In order to distinguish the salty water freeze-thaw and fresh water freeze-thaw, we use different symbols when marking concrete specimens. The specimens used to test dynamic elastic modulus in salt water freeze-thaw are called S-T test group, while in the fresh water freeze-thaw are called W-T. And the control group for the dynamic elastic modulus are called $\mathrm{C}$. The specimens used to test compressive strength in salty water freeze-thaw are called S-T, while the control group are called S-C. The specimens used to test compressive strength in fresh water freeze-thaw are called W-T test group, while the control group are called W-C.

\subsection{Test method}

\subsubsection{Freeze-thaw cycle text.}

The freeze-thaw test process refers to the quick freezing method in Standard for Test Methods of Long-Term Performance and Durability of Ordinary Concrete (GB/T 50082-2009) [6]. During the salty water freeze-thaw test, $3 \% \mathrm{NaCl}$ solution is put into the test box, and then the test specimens cured to 28 days are put into the test box for 300 times of salt water freeze-thaw test. The control group are still maintained in the standard curing room until the test group complete 300 freeze-thaw cycles in the salty water. After 25 freeze-thaw cycles, the specimens are taken out to test the transverse fundamental frequency, and the dynamic elastic modulus are calculated. The only difference between fresh water freeze-thaw test and salty water freeze-thaw test is that the drinkable tap water put into the test box. 


\subsubsection{Compressive strength test.}

When the S-T test group are carried out the salty water freeze- thaw test, the control group S-C are maintained in the standard curing room. After 300 cycles of salty water freeze- thaw, the S-T test group is taken out, and meanwhile the S-C control group is taken out from the standard curing room. The compressive strength of the S$\mathrm{T}$ test group and the S-C control group are tested. The compressive strength test method of fresh water freezethaw is the same as that of salty water freeze-thaw. According to " Standard for Test Methods of Concrete Physical and Mechanical Properties "( GB/T 50081-2002) [7], the compressive strength test is carried out on the electro-hydraulic servo universal testing machine.

\subsubsection{Micro pore structure test.}

The test blocks which have finished 300 freeze-thaw cycles are tested the dynamic elastic modulus firstly, and then they are broken into larger concrete blocks with a hammer. The concrete blocks are put into the laboratory and crushed by the small jaw crusher. The broken particles were passed through the sieve of $2.36 \mathrm{~mm}$ and $4.75 \mathrm{~mm}$, the residual material on the $2.36 \mathrm{~mm}$ sieve about $1 \mathrm{~kg}$ was placed in a white platter under natural light. Then the nonneedle-flake pure mortar particles were selected and weighed at will. It is required that the mortar particles should not be coated with the original sand stone, and should not contain the forming surface. $20 \mathrm{~g}$ qualified mortar particles were weighed for use. The mortar particles were taken out after being cleaned for 5 minutes by microwave cleaning machine, and then were placed and spread in a tray. The mortar particles were dried at $65^{\circ} \mathrm{C}$ in the air-blast drying oven, until the weight difference between the two weighting is about $1 \%$. After drying, the mortar particles were taken out in a dryer, and cooled naturally. The hole structure data were measured and collected by 9510 automatic mercury intrusion porosimeter.

\section{Results and analysis}

\subsection{Decay law of concrete mechanical properties under freeze-thaw cycle}

\subsubsection{Compressive strength.}

The compressive strength of the test blocks after the salty water freeze-thaw cycle and fresh water freeze-thaw cycle is summarized in Table 4. The compressive strength of concrete under salty water freeze-thaw cycle decreases by about $40 \%$, while the reduction range of concrete compressive strength under fresh water freeze-thaw cycle is only $16 \%$. It shows that the damage effect on concrete compressive strength under salty water freeze-thaw cycle is more significant than that under fresh water freeze-thaw cycle.
Table 4. Compressive strength of cement concrete.

\begin{tabular}{cccc}
\hline $\begin{array}{c}\text { Types of } \\
\text { freeze- } \\
\text { thaw } \\
\text { cycle }\end{array}$ & $\begin{array}{c}\text { Specimen } \\
\text { number }\end{array}$ & $\begin{array}{c}\text { Compressive } \\
\text { strength (MPa) }\end{array}$ & $\begin{array}{c}\text { Reduction } \\
\text { range(\%) }\end{array}$ \\
\cline { 1 - 3 } $\begin{array}{c}\text { Salty } \\
\text { water }\end{array}$ & S-T & 31.0 & 40 \\
\cline { 1 - 3 } $\begin{array}{c}\text { Fresh } \\
\text { water }\end{array}$ & W-T & 51.4 & 40 \\
\hline
\end{tabular}

\subsubsection{Dynamic elastic modulus and mass lost.}

The dynamic elastic modulus of concrete can reflect the internal damage of specimens after freeze-thaw cycles. From the Figure 1, it can be seen that dynamic elastic modulus of the control group $\mathrm{C}$ slightly with the increase of curing age. The dynamic elastic modulus of concrete under salty water freeze-thaw cycle decreases more than that under fresh water freeze-thaw cycle. One reason this may be the case is that the chloride ions in the salty water penetrate into the concrete from the pores during the freeze-thaw cycle and deposit in it, and more and more sediments are deposited with the development of freeze-thaw cycles. At last the freezing pressure of salty water frost heaving makes the internal damage of concrete more serious.

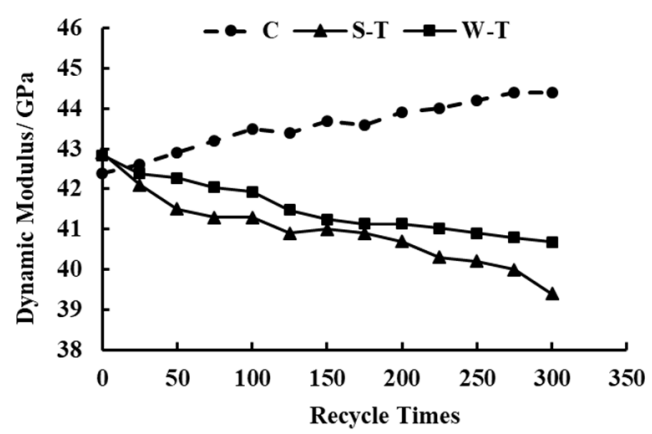

Figure 1. Dynamic elastic modulus VS times of freeze-thaw cycle.

The dynamic elastic modulus before and after 300 freeze-thaw cycles are listed, as shown in Table 5. From the Table 5, it can be seen that the dynamic elastic modulus after 300 salty water freeze-thaw cycles decreases by about $8 \%$, while the reduction range of dynamic elastic modulus after 300 fresh water freeze-thaw cycles is only $5 \%$. It shows that the damage effect under salty water freeze-thaw cycle is more serious than that under fresh water freeze-thaw cycle.

Table 5. Dynamic elastic modulus before and after freeze-thaw cycle.

\begin{tabular}{cccc}
\hline & \multicolumn{2}{c}{$\begin{array}{c}\text { Dynamic elastic modulus } \\
(\mathrm{GPa})\end{array}$} & Reduction \\
\cline { 2 - 3 } $\begin{array}{c}\text { Specimen } \\
\text { number }\end{array}$ & $\begin{array}{c}\text { before } \\
\text { freeze-thaw } \\
\text { cycle }\end{array}$ & $\begin{array}{c}\text { After } 300 \\
\text { freeze-thaw } \\
\text { cycles }\end{array}$ & range(\%) \\
\hline S-T & 42.9 & 39.4 & 8 \\
\hline W-T & 42.8 & 40.7 & 5 \\
\hline
\end{tabular}


The mass changes of concrete during the freeze-thaw cycle are plotted in Figure 2. From the Figure 2, it can be seen that the mass of control group specimens which are placed in the standard curing room all the time is basically unchanged. The salty water freeze-thaw cycle and fresh water freeze-thaw cycle can reduce the mass of concrete, which is mainly manifested in the surface concrete falling off the specimen. The mass loss of concrete under the salty water freeze-thaw cycle is larger than that under fresh water freeze-thaw cycle. According to the calculation, the mass loss of test group S-T specimens under salty water freeze-thaw cycle is $2 \%$, while that of test group $\mathrm{W}-\mathrm{T}$ specimens under the fresh water freeze-thaw cycle is about $1 \%$. The mass loss caused by salty water freezethaw cycle is about 2 times that of fresh water freeze-thaw cycle.

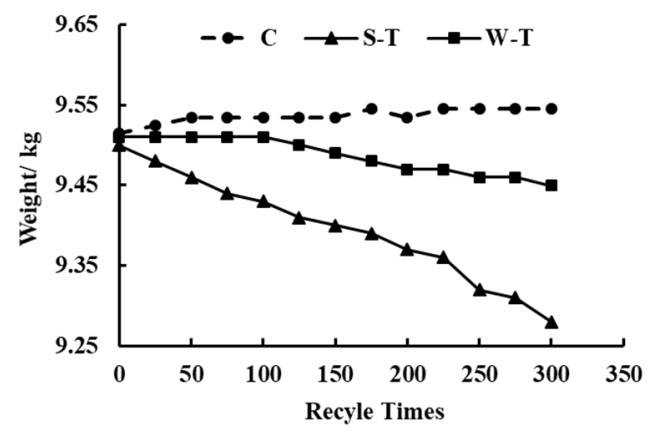

Figure 2. Mass VS times of freeze-thaw cycles.

Therefore, from the perspective of dynamic modulus and mass loss, it can be find that even the frost resistant concrete with fly ash and air entraining agent can also be degraded by freeze-thaw cycle, and the damage of salty water freeze-thaw cycle is more serious than that of fresh water freeze-thaw cycle.

\subsection{Decay law of concrete microstructure under freeze-thaw cycles}

Many studies have shown that the change of macro properties of concrete is closely related to the decay of microscopic structure [8-9]. In order to explore the deterioration mechanism of concrete mechanical properties caused by salty water freeze-thaw cycle and fresh water freeze-thaw cycle, this study analyzes the deterioration of concrete caused by freeze-thaw cycle from the perspective of microscopic pore structure.

\subsubsection{Parameters of concrete pore structure. Porosity} refers to the percentage of the internal pore volume to its total volume. The study shows that the porosity reflects the compactness of concrete. When the porosity increases, the concrete will be more loose, while the compressive strength of concrete will be decrease[10]. The average pore diameter can be used to describe the pore size of materials in general. The study shows that the larger the average pore, the looser the concrete pore structure[11]. The critical pore diameter refers to the maximum pore size of the pore which can connect the larger pores, it reflects the connectivity of pores and the tortuosity of seepage path in concrete. The study shows that the interconnected channels are more easily formed inside the concrete with the larger critical pore size[12]. Table 6 lists the measured values of porosity, average pore diameter and critical pore diameter, which are closely related to the concrete mechanical properties.

Table 6. Parameters of concrete pore structure.

\begin{tabular}{ccccc}
\hline $\begin{array}{c}\text { Types } \\
\text { of } \\
\text { freeze- } \\
\text { thaw } \\
\text { cycle }\end{array}$ & $\begin{array}{c}\text { Specimen } \\
\text { number }\end{array}$ & Porosity $(\%)$ & $\begin{array}{c}\text { Average } \\
\text { pore } \\
\text { diameter } \\
(\mathrm{nm})\end{array}$ & $\begin{array}{c}\text { Critical } \\
\text { pore } \\
\text { diameter } \\
(\mathrm{nm})\end{array}$ \\
\hline $\begin{array}{c}\text { Salty } \\
\text { water }\end{array}$ & S-T & 27.59 & 21 & 825 \\
\cline { 2 - 5 } $\begin{array}{c}\text { Fresh } \\
\text { water }\end{array}$ & W-C & 20.08 & 18 & 422 \\
\cline { 2 - 5 } & W-C & 25.27 & 19 & 6038 \\
\hline
\end{tabular}

The Table 6 shows that the porosity and the average pore diameter increases after freeze-thaw cycles, it means that the concrete becomes more porous after freeze-thaw cycles, which is also the reason for the decrease of concrete compressive strength and dynamic elastic modulus. According to the calculation in the table, the concrete porosity after salty water freeze-thaw cycles increases by $37 \%$, while that only increases by $9 \%$ after fresh water freeze-thaw cycles, The decay law of porosity is consistent with that of compressive strength, so it can be seen that the freeze-thaw cycle increases the porosity of concrete, which leads to the decrease of compressive strength. The critical pore diameter of concrete after salty water freeze-thaw cycles is almost doubled, while that after fresh water freeze-thaw cycles is about 1/3 larger than before. After the freeze-thaw cycles, the critical pore diameter gets larger and the internal pores of concrete are more easily connected, thus forming a seepage channel. Considering the changes of porosity, average pore diameter and critical pore diameter, it can be seen that compared with the fresh water freeze-thaw cycles, the degradation of internal pore structure is more serious and the seepage channels are more easily formed after salty water freeze-thaw cycles. The macroscopic performance is that the compressive strength, dynamic elastic modulus and impermeability are reduced.

\subsubsection{Pore diameter distribution.}

The pore diameter distribution of control group $\mathrm{C}$, test group S-T after salty water freeze-thaw cycles and test group W-T concrete after fresh water freeze-thaw cycles are plotted in Figure 3.

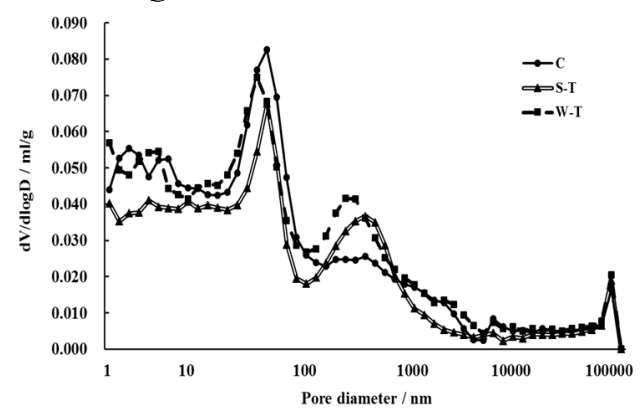

Figure 3. Pore diameter distribution of concrete. 
The Figure 3 shows that compared with the control group, after salty water freeze-thaw cycles, the amount of pores whose diameter is between $100 \mathrm{~nm}$ and $1000 \mathrm{~nm}$ increases, while the amount of pores whose diameter is under $100 \mathrm{~nm}$ decreases. After the fresh water freeze-thaw cycles, the amount of pores whose diameter is between $100 \mathrm{~nm}$ and $1000 \mathrm{~nm}$ also increases. The results show that no matter salty water freeze-thaw cycles or fresh water freeze-thaw cycles, the concrete capillary pores will increase, and the concrete is easy to absorb water, which makes the concrete occur frost heaving damage easily. The Figure 3 shows that after salty water freeze-thaw cycles, the pore diameter of concrete becomes larger, and the whole pore diameter distribution curve moves to the large hole, which indicates that the whole concrete pore structure is deteriorated after salty water freeze-thaw cycle. However, the pore diameter distribution curve don 't move to the right after the fresh water freeze-thaw cycle, but the pore content with pore diameter distribution of 10-100 nm decreases. The results indicate that the concrete pore structure also deteriorates after the fresh water freezethaw cycles, mainly manifests as the decrease of small holes and the increase of large pores.

\section{Conclusions}

Be aimed at the salty water freeze-thaw cycles and fresh water freeze-thaw cycles, the mechanical properties of concrete and the decay law of micro pore structure under the two situations are experimentally studied. The compressive strength, dynamic elastic modulus, mass loss, micro pore structure parameters are measure and the pore diameter distribution curve are drawn. This paper explores the essence of concrete mechanical properties change from the perspective of microcosmic pore structure. The conclusions are summarized as follows:

- The compressive strength and dynamic elastic modulus of concrete will decrease after freeze-thaw cycles. The decline range after salty water freeze-thaw cycles is greater than that after fresh water freeze-thaw cycles.

- The concrete mixed with fly ash and air entraining agent can also be deteriorated by freeze-thaw cycle, and the extent of damage under salty water freezethaw cycle is greater than that under fresh water freezethaw cycle.

- The concrete porosity after salty water freezethaw cycles increases by $37 \%$, while that only increases by $9 \%$ after fresh water freeze-thaw cycles, so it can be seen that the freeze-thaw cycle increases the porosity of concrete, which leads to the decrease of compressive strength.

- $\quad$ The critical pore diameter of concrete after salty water freeze-thaw cycles is almost doubled, while that after fresh water freeze-thaw cycles is about 1/3 larger than before. After freeze-thaw cycles the internal pore channels of concrete are more connected, which makes it easier to form seepage channels.

- After the freeze-thaw cycle, the amount of pores whose diameter is between $100 \mathrm{~nm}$ and $1000 \mathrm{~nm}$ increases, while the amount of pores whose diameter is under $100 \mathrm{~nm}$ decreases. After salty water freeze-thaw cycles, the pore diameter distribution curve tends to move to the right, and the whole concrete pore structure is deteriorated.

- The mechanical properties of concrete is degraded by deteriorating the micro pore structure in the freeze-thaw cycles, and the concrete deterioration caused by salty water freeze-thaw cycle is more serious than that of fresh water freeze-thaw cycle.

\section{References}

1. Highway Planning and Design Institute of the Ministry of Communications. (1986) Standard of Climatic Zoning for Highway. China Communications Press, Beijing.

2. Chen, J.Z., Zhao, T.J,. Wang, Y.H., Wang, P.G. (2019) Study on Cl- Penetration Resistance and Frost Resistance of Concrete in Marine Environment in Cold Region. China Concrete and Cement Products, 9:24 -28.

3. Guo, C. (2016) .research of technology of reparation and cause of concrete's freeze-thaw damage about port structures. Tianjin University.

4. Zhang, Y.C., Li, Q.N.(2016) Study on Freeze-Thaw Resistance of Concrete based on Pore Structure analysis. Highway, 3:182-186.

5. Zheng, Y.X., Yang, P.B., Kang, H.G.(2016) The Overview of Concrete Structure Durability under the Freeze-thaw Condition. Journal of Zhengzhou University (Engineering Science), 37(5):27-32.

6. Ministry of Housing and Urban-Rural Development of the People's Republic of China(MOHURD). (2009)Standard for Test Methods of Long-Term Performance and Durability of Ordinary Concrete. China Architecture \& Building Press, Beijing.

7. Ministry of Housing and Urban-Rural Development of the People's Republic of China(MOHURD). (2002) Standard for Test Methods of Concrete Physical and Mechanical Properties. China Architecture \& Building Press, Beijing.

8. Yu, L. (2013) Study on Durability of Cement Concrete in Multi Erosion Environments. Beijing University of Technology.

9. Wang, C., Liu, Z.L., Yu, L. (2018) Relationship between Anti-frozen Durability and Pore Structure on Concrete in Freeze and Thaw Cycle Environment. MATEC web of Conferences, 238: 64-68.

10. Yu, L., Zhang, S.X., Chen, L. (2018) Anti-acid Corrosion Property Concrete Improved by Microstructure Optimizing. MATEC Web of Conferences, 238: 56-59.

11. Zhang, J.X., Wang, J.G., Ran, J.(2016) Influence of Different Deterioration Effects on Mechanical Properties of Concrete. Concrete, 11: 52-55.

12. Yu, L. (2017) Micro-Properties of Cement Concrete. China Architecture \& Building Press, Beijing. 